\title{
1 Unravelling the complex genetic basis of growth in New 2 Zealand silver trevally (Pseudocaranx georgianus)
}

3 Noemie Valenza-Troubat ${ }^{1}$, Sara Montanari ${ }^{1}$, Peter Ritchie ${ }^{2}$, and Maren Wellenreuther ${ }^{1,3,{ }^{*}}$

$6 \quad{ }^{1}$ The New Zealand Institute for Plant \& Food Research Ltd, Nelson, New Zealand

$7{ }^{2}$ School of Biological Sciences, Victoria University of Wellington, Wellington, New Zealand

$8{ }^{3}$ School of Biological Sciences, The University of Auckland, Auckland, New Zealand

9

10

11

12 \#corresponding author Maren.Wellenreuther@plantandfood.co.nz

13

14

15

16

17 Keywords: Linkage map, QTL, GWAS

18 


\section{Abstract}

20 Growth directly influences production rate and therefore is one of the most important and

21 well-studied trait in animal breeding. However, understanding the genetic basis of growth

22 has been hindered by its typically complex polygenic architecture. Here, we performed

23 quantitative trait locus (QTL) mapping and genome-wide association studies (GWAS) for

2410 growth traits that were observed over two years in 1,100 $F_{1}$ captive-bred trevally

25 (Pseudocaranx georgianus). We constructed the first high-density linkage map for trevally, 26 which included 19,861 single nucleotide polymorphism (SNP) markers, and discovered 27 eight QTLs for height, length and weight on linkage groups 3, 14 and 18. Using GWAS, we 28 further identified 113 SNP-trait associations, uncovering 10 genetic hot spots involved in 29 growth. Two of the markers found in the GWAS co-located with the QTLs previously 30 mentioned, demonstrating that combining QTL mapping and GWAS represents a powerful 31 approach for the identification and validation of loci controlling complex traits. This is the 32 first study of its kind for trevally. Our findings provide important insights into the genetic 33 architecture of growth in this species and supply a basis for fine mapping QTLs, marker34 assisted selection, and further detailed functional analysis of the genes underlying growth 35 in trevally. 
Introduction

39 Growth facilitates essential functions such as reproduction or the ability to adapt to 40 environments. Although there are exceptions, increase in body size is usually positively 41 correlated with numerous fitness traits such as higher mating success and fecundity, 42 increased offspring quality and lengthened longevity (Gebhardt-Henrich and Richner 1998, 43 Dmitriew 2011). Most vertebrates exhibit a finite amount of growth. In fish, however, the 44 process of growing is indeterminate, or indefinite, and continues throughout their life (Weatherley 1972), although the rate tends to decline as body size increases (Pedersen and Jobling 1989). This highly complex process is the result of interactions between environmental effects and genetic differences. Factors including sex (e.g. Imsland and Jonassen 2003), age or food availability (e.g. Jones 1986) influence growth rate, as well as abiotic factors changing seasonally such as temperature (e.g. Karås and Klingsheim 1997, Imsland, Schram et al. 2007), photoperiod (e.g. Imsland and Jonassen 2003) or oxygen levels (e.g. Brett and Groves 1979). The genetic basis of growth traits is typically highly polygenic (Wellenreuther and Hansson 2016). Functional relationships between genetic variations and physiological parameters of growth have been described in commercially relevant species such as cod (Gadus morhua) (see review by: Imsland and Jónsdóttir 2002), Atlantic salmon (Salmo salar) (Tsai, Hamilton et al. 2015) or tilapia (Tilapia mossambica) (Liu, Sun et al. 2014), but are still poorly understood in many nonmodel species.

With the development of next generation sequencing technologies (NGS) the cost of highdensity genotyping has drastically decreased, therefore enabling the more widespread application of quantitative trait locus (QTL) mapping experiments. Many variants associated with complex phenotypes have since been found in a variety of non-model species. However, QTL mapping approaches only allow the identification of genetic 63 regions that are polymorphic between two parents, and relevant in a particular 64 environment, therefore potentially missing some common variants associated with the 65 traits (Mackay 2001). For this reason the location and effects of detected QTLs can vary between mapping populations. For example, in the Atlantic salmon, QTLs involved in growth have been found on different linkage groups according to different studies (Baranski, Moen et al. 2010, Tsai, Hamilton et al. 2015, Besnier, Solberg et al. 2020). 
69 Recently, genome-wide association studies (GWAS) have been widely employed to detect 70 QTLs both in captive (Palaiokostas, Kocour et al. 2018) and natural populations (Santure 71 and Garant 2018). This technique identifies associations between markers and 72 phenotypes based on linkage disequilibrium (LD) (Meuwissen and Goddard 2010). 73 Compared with QTL mapping, GWAS can be conducted on genetically diverse, unrelated 74 individuals and is particularly advantageous when controlled crossing and generation of 75 large segregating populations is difficult. GWAS has proved useful for the identification of 76 loci associated with numerous growth traits in fish (e.g. Yang, Wu et al. 2020). However, 77 the power of GWAS relies on the number of markers in relation to the extent of linkage 78 disequilibrium in the population (Newell, Cook et al. 2011). When applied to natural 79 populations or collections of outcrossing individuals, characterised by a rapid linkage 80 disequilibrium decay, tens of thousands of markers are often required to obtain an 81 adequate level of resolution. Because of the intrinsic limitations of statistical methods 82 comparing thousands of tests, GWAS has a higher frequency of false discovery of loci 83 than QTL mapping (Hayes, Lewin et al. 2013). A final disadvantage of GWAS is its low 84 power for detecting rare allelic variants. However, their frequency can be increased in controlled crosses and therefore captured with QTL mapping. Hence, combining GWAS and QTL mapping often gives more complete and reliable results than using one of the methods alone (Fraslin, Quillet et al. 2020).

Aquaculture is the fastest growing food-production sector in Aotearoa New Zealand. 89 Currently, the local industry relies almost exclusively on the farming of three species: 90 Greenshell $^{\mathrm{TM}}$ mussels (Perna canaliculus), Pacific oysters (Crassostrea gigas) and only 91 one finfish, king/chinook salmon (Oncorhynchus tshawytscha), which is an introduced species (Camara and Symonds 2014, Symonds, Clarke et al. 2019). Hence, there is a strong interest in diversifying the range of species available for aquaculture. The native finfish silver trevally (Pseudocaranx georgianus, Cuvier 1833) has been identified as a suitable candidate for New Zealand aquaculture. In Aotearoa, its Māori name is araara. Indigenous Māori people have a strong cultural connection to trevally, where it is considered as taonga (i.e. has value, or is treasured). Trevally is a shoaling pelagic 98 species found throughout the coastal waters of southern Australia and around New 99 Zealand (Smith-Vaniz and Jelks 2006). It is most common at depths of approximately 80 100 $\mathrm{m}$, although its range is thought to be 10-238 $\mathrm{m}$ and can reach over 40 years of age 
101 (Ministry for Primary Industries 2014, Bray 2020). In many regions of New Zealand, 102 trevally is a major component of recreational and commercial fisheries (Ministry for 103 Primary Industries 2014). For it to be suitable for commercial aquaculture, however, 104 trevally's growth rate must be improved, which can be done using selective breeding 105 (Valenza-Troubat, Montanari et al. 2021).

106 In this study, we investigated the genetic architecture of 10 growth traits in a new 107 population of trevally. More specifically, we genotyped and phenotyped $1,100 \mathrm{~F}_{1}$ trevally to 108 1) generate a high-density linkage map, 2) detect rare QTLs associated with growth using 109 linkage mapping in a sub-family comprising 89 individuals, 3) identify common SNPs 110 associated with growth using GWAS on the whole population, and 4) overlap the results 111 and annotate supported regions.

\section{Methods}

\section{Study population}

114 The trevally population used in this study was generated as part of a breeding programme 115 started at the Plant and Food Research (PFR) finfish research facility in Nelson, New 116 Zealand. The full description of holding conditions and pedigree are described in Valenza117 Troubat et al. (2021). Briefly, the population comprised of 13 wild caught $F_{0}$ broodstock 118 and 1,100 $F_{1}$ captive-bred offspring. In 2015, induced mass spawning of the $F_{0}$ generation 119 in a single tank was used to produce the offspring $F_{1}$ generation. This resulted in a 120 complex pedigree, including a combination of unrelated, full- and half-siblings in the $F_{1}$ 121 generation. $F_{1}$ offspring were held in a single tank from hatch receiving the same feeding 122 regime, light, water flow and aeration until the end of this experiment. The seawater tanks 123 in the facility are located on the seaward side of Port Nelson and receive ambient 124 seawater from an underground bore which is filtered using mesh filters and UV treatment.

\section{Phenotyping and trait estimation}

126 Ten growth traits were used in the current study, namely peduncle length (PL), height at $12725(\mathrm{H} 25), 50(\mathrm{H} 50)$ and $75 \%(\mathrm{H} 75)$ of the $\mathrm{PL}$, estimated weight (EW) and related net gain 128 traits $(\Delta \mathrm{PL}, \Delta \mathrm{H} 25, \Delta \mathrm{H} 50, \Delta \mathrm{H} 75$ and $\Delta \mathrm{EW}$, respectively) (Valenza-Troubat, Montanari et al. 129 2021). These measurements were recorded on three occasions throughout the 
experiment, at the beginning (November 2017), in the middle (October 2018), and at the end (November 2019), when the fish were a little over two, three and four years old, respectively.

Using the

Morphometric

Software ${ }^{\mathrm{TM}}$

(https://www.plantandfood.co.nz/page/morphometric-software-home/), the outline of each fish was extracted from images and morphometric were located, and then used to make measurements. PL was measured by assessing the distance between the upper lip and narrowest cross-section of the tail. Height was measured at three positions along the fish: 25,50 , and $75 \%$ of the PL. The weight estimations (EW) were done following a Bayesian hierarchical approach as described in Froese et al. (2014). The net gain for each trait was calculated as the difference from the initial measurement (November 2017) with subsequent ones. The normality of the data was assessed visually using Quantile-Quantile (QQ) plots generated in the R statistical environment version 3.2.3 (R Development Core Team 2016).

\section{Genotyping and variant calling}

144 Samples of fin tissue from 13 tagged $F_{0}$ and 1,100 $F_{1}$ individuals were collected and stored 145 as described in Valenza-Troubat et al. (2021). Total DNA was extracted as described in 146 Ashton et al. (2019) with minor modifications, and then quantified and quality-checked by 147 fluorescence, spectrophotometry and agarose gel electrophoresis. The $13 F_{0}$ individuals were whole genome sequenced (paired-end, 125 bp reads) over three lanes of the HiSeq 2500 platform at the Australian Genome Research Facility (AGRF, Melbourne, Australia). The $F_{1}$ were genotyped using a modified GBS approach (Elshire, Glaubitz et al. 2011), as described in Valenza-Troubat et al. (2021). A total of 12 pools of 96 samples each were prepared and sent to AGRF for sequencing on a HiSeq 2500 platform (single-end, $100 \mathrm{bp}$ reads). Sequencing data quality for both $F_{0}$ and $F_{1}$ generations were checked using FastQC v0.11.7 (Andrews 2010). Raw reads from the $F_{0}$ were trimmed using trimmomatic v0.36 (Bolger, Lohse et al. 2014) (using the parameters HEADCROP: 9, TRAILING: 10, SLIDINGWINDOW: 5:20, MINLEN: 75). The $F_{1}$ samples were de-multiplexed from the 12 sequencing libraries using the process_radtags module available in the STACKs version 2.1 pipeline (Catchen, Hohenlohe et al. 2013) and the reads were trimmed using Fastqmcf in ea-utils v1.1.2-806 (minimum sequence length $=50$, quality threshold causing base removal = 33) (Aronesty 2013). Read groups were added to all sequences and bam files were sorted and indexed using Picard toolkit (Broad_Institute 2015). Reads were then 
mapped to the reference genome (Catanach, Ruigrok et al. 2021) using the BurrowsWheeler Aligner (BWA) v0.7.17 (Li \& Durbin, 2009) and variants were called jointly with the parallel module of freebayes v1.3.1 (Garrison and Marth 2012), with minimum of five observations and minimum mapping quality of 10. The SNPs with single-sample sequence coverage (sequencing depth)<3 were removed to reduce the number of putatively erroneous genetic variants, and missing data and minor allele frequency (MAF) were set to $<20 \%$ and $>0.05$, respectively.

\section{Linkage map construction and QTL identification}

170 The parents of each $F_{1}$ individual in the dataset were identified with Sequoia v2.0.7 171 (Huisman 2017) as reported in Valenza-Troubat et al. (2021). The full SNP dataset (i.e. before the stringent filtering performed for the parentage analysis) was filtered for Mendelian errors (> 5\%), and checked for distorted segregation using a chi-square test with $\alpha=0.05$. The linkage map was constructed in Lep-MAP v3.0 (Rastas, Paulin et al. 2013), using the largest family. Markers were separated into linkage groups (LG) with the

SeparateChromosomes module (logarithm of odds (LOD) limit =14, minimum markers per $L G=50)$. The order of the markers was computed with the OrderMarkers module. Single markers at the end of each LG were removed if they were more than $3 \mathrm{cM}$ apart from the next closest marker. MapChart v2.32 (Voorrips 2002) was used to visualise the genetic map. As the $F_{0}$ were assumed to be outbred, the linkage map and the genotypes of the mapping family were input as a 4-way cross in the $R$ package $R / q$ tl version 1.47-9 (Broman, Wu et al. 2003) for interval mapping. Standard interval mapping was performed and a genome-wide permutation test (Doerge and Churchill 1996) with 1000 permutations was used to determine the LOD significance thresholds ( $p$-value $=0.05)$.

\section{Genome-Wide Association Study}

186 GWAS was carried out on the entire genotyped $F_{1}$ population $(n=1100)$. SNPs were 187 removed if the call rate was smaller than 0.8 , MAF $<0.01$, if Mendel error rate $>5 \%$ 188 (based on trios identified with the parentage analysis carried out above), and they were 189 LD-pruned using an $r^{2}>0.80$ in a $50 \mathrm{~kb}$ sliding window with five variants. Association 190 analysis were performed using the Fixed and random model Circulating Probability 191 Unification (FarmCPU) method (Liu, Huang et al. 2016) implemented in GAPIT3 v3.1.0 192 (Wang and Zhang 2021). A Bayesian information criterion (BIC)-based model selection 
was used to find the optimal number of principal components (PCs) for each time measure, to account for family and population structure. The cut-off for significant association was a False Discovery Rate (FDR) adjusted $p$-value $=0.05$ (Benjamini and Hochberg 1995), to control for multiple testing. To assess how well the model used in GWAS accounted for population structure and family relatedness, results of the GWAS were visualised with $Q Q$ plots implemented in GAPIT3, which depicted the distribution of the actual $p$-values compared with the theoretical ones. Manhattan plots were used to visualise the SNPs associated with the different phenotypes, using the physical position of the markers on the reference genome.

\section{Ethics statement}

All research carried out in this study was reviewed and approved by the animal ethics committee of Victoria University of Wellington in New Zealand (Application number 25976).

\section{Results}

\section{Phenotypic values of growth traits}

207 All offspring were phenotyped at the first measurement (November 2017), while numbers 208 decreased at the two subsequent time points because of natural mortality that occurred 209 during the study. All traits showed a normal distribution and exhibited large levels of 210 phenotypic variation, as discussed in Valenza-Troubat et al. (2021) A summary of the 211 mean values and standard deviations of the 10 growth phenotypes is shown in Table 1. In 212 both the family used for QTL mapping and in the entire population used for GWAS, a 213 normal distribution of the residuals was observed for the ten traits investigated (Figure 1). 214 Transgressive lines (i.e. offspring that have more extreme phenotypes than the parents) 215 were observed in the population.

\section{High-density linkage map}

217 Sequencing of the 13 parental fishes generated 1.23 billion reads, corresponding to an 218 average genome coverage of 13x per individual. Of the 1,100 offspring, $1094 \mathrm{~F} 1$ were 219 successfully genotyped via GBS, resulting in 0.42x genome coverage per individual fish. 220 Variant calling and basic quality filtering generated a dataset of 171,923 SNPs. Overall, 21 221 families from 10 out of the 13 sequenced F0 fishes were identified by Valenza-Troubat et 
222 al. (2021) when reconstructing the pedigree of the population. The largest family included

22387 offspring and was used to assemble the sex-averaged linkage map. A total of 21,665 224 SNPs were polymorphic in this family and passed the chi-square test, and 19,861 were 225 successfully mapped to 24 Linkage groups, 1,830 after removal of the co-mapping loci 226 (Figure 2). LG numbers were randomly assigned, as no previous reference had been 227 published. The genetic map spanned 1,335.46 cM, with an average marker distance of $2280.73 \mathrm{cM}$. The largest gap was on LG14 and was $4.10 \mathrm{cM}$ long. The longest and shorter 229 Linkage groups were $17(82.89 \mathrm{cM})$ and $8(48.14 \mathrm{cM})$, respectively (Table 2).

\section{QTL mapping revealed rare variants associated with growth}

231 The genome-wide significant thresholds for QTL mapping were established at LOD values 232 between 4.60 and 4.81 for the ten phenotypic traits across three years (Table 3). In total, 233 eight significant QTLs were identified on four locations in three linkage groups (Figure 3). 234 Six of these QTLs were for traits recorded during the first measurement (November 2017), 235 and two for the last measurement (November 2019). In particular, three QTLs detected for $236 \mathrm{H} 25, \mathrm{PL}$ and EW measured at the first time point co-mapped on LG3 (between 23.2 and $23724.9 \mathrm{cM})$. A second QTL was mapped to LG3 at $52.1 \mathrm{cM}$ for $\mathrm{H} 75$ from the first 238 measurement. Additionally, the traits PL and EW from 2017 were associated to a second 239 locus, at the top of LG18. The percentage of phenotypic variance explained (PVE) by the 2402017 QTLs ranged from 22.1 to $25.3 \%$. In the last measurement two QTLs for $\Delta \mathrm{H} 75$ and $241 \Delta \mathrm{PL}$ were found to co-map to LG14 (between 17 and $17.1 \mathrm{cM}$ ), with PVE of 39.7 and 31.1, 242 respectively (Table 3). No QTLs were found for the middle measurement (October 2018) 243 and for all other traits in 2017 and 2019.

\section{Genome-wide association found strongly associated SNPs}

245 A total of 1,024 F1 individuals had both genotypic and phenotypic data for all 246 measurements. After filtering based on Mendelian errors, MAF and LD pruning, 107,067 247 SNPs were left and used in the GWAS. Model selection in GAPIT resulted in no PCs to be 248 used as co-variates in any of the traits (Figure 4A). QQ plots showed that FarmCPU 249 adequately accounted for the confounding effects of family and population structure 250 (Figure 4B). A total of 93 SNPs were significantly associated $(-\log 10(\rho)>7.03)$ with at 251 least one of the ten traits measured at each year of phenotyping (Figure 4C, Table S1). 252 Only $\Delta \mathrm{H} 75$ in October 2018 and November 2019 had no significant association. Of the 93 
253 SNPs, 15 were associated with more than one trait. These included four, seven and four

254 SNPs associated with measurements at the first, second and third time point, respectively.

255 No common SNPs were identified among different years. Significant associations were in 256 some cases found for SNPs less than $0.5 \mathrm{Mb}$ apart, highlighting hot spots on chromosomic 257 regions. A total of 10 hot spots were identified: two on LG1, one on LG2, two on LG3, two 258 on LG5, one on LG6, one on LG10 and one on LG18. Six of these included associations 259 for traits measured in different years (Table S1).

\section{Discussion}

261 We constructed the first genetic map for trevally, and we were able to use this map to determine genomic regions associated with phenotypic growth traits. Our map included 19,861 SNPs across 24 linkage groups and confirmed the 24 mega-scaffolds of the trevally reference genome (Catanach, Ruigrok et al. 2021). A linkage map built for yellowtail kingfish (Seriola lalandi), the closest species to trevally for which a map has been constructed, was also resolved into 24 linkage groups (Nguyen, Rastas et al. 2018), consistent with our findings. The map built here for trevally was 1,335.46 cM in length, which is within the range of map length expected for many teleost fish. For example, the map assembled here is longer when compared to the yellowtail kingfish map, similar in length to the map of the Australasian snapper (Chrysophrys auratus) (Ashton, Ritchie et al. 2019) and shorter when compared to the European sea bass (Dicentrarchus labrax) (Griot, Allal et al. 2021).

Eight significant QTLs related to growth were mapped to three of the trevally linkage groups. Other studies in teleost have found multiple QTLs affecting growth such as in Atlantic salmon (Tsai, Hamilton et al. 2015, Besnier, Solberg et al. 2020), Australasian snapper (Ashton, Ritchie et al. 2019), spotted sea bass (Lateolabrax maculatus) (Liu, Wang et al. 2020) or yellowtail kingfish (Nguyen, Rastas et al. 2018), supporting the hypothesis of a polygenic regulation. No significant QTLs were identified with QTL mapping for the second time point, October 2018. In the segregating family used for QTL mapping, the number of offspring decreased from 87 in 2017 to 68 in 2018 and 67 in 2019 as the result of natural mortality. Although some statistically significant QTLs were found in the measurements made in the latter period of the experiments, the smaller sample sizes 
284 absence of QTLs detected in October 2018. Indeed, sample size is known to influence the power of a study to detect QTLs (Hong and Park 2012), and is regularly discussed as one of the most important concerns when designing a mapping experiment (Ashton, Ritchie et al. 2017). Interestingly, two traits (Peduncle Length and Estimated Weight) shared the same QTLs on two linkage groups in the first measurement period (November 2017). This is consistent with the level of high genetic and phenotypic correlations reported for body length and body weight (Valenza-Troubat, Montanari et al. 2021). These findings suggest that selection applied on easily measurable traits such as length will result in the concomitant improvement of more difficult to assess, yet valuable, growth traits (such as weight) in the breeding of trevally.

GWAS identified 113 associations with growth, corresponding to 93 different SNPs spanning 22 LGs, further supporting the hypothesis of a polygenic basis of growth-related traits in trevally. Growth is considered as a complex trait and has been found to be polygenic across the tree of life, in very diverse taxa from plants, like in the model species Arabidopsis thaliana (Wieters, Steige et al. 2021), to vertebrates like humans (SinnottArmstrong, Tanigawa et al. 2021) and other fish species (e.g. Liu, Sun et al. 2014, Yang, Wu et al. 2020, Debes, Piavchenko et al. 2021). In our study, a lower number of loci were found with the QTL mapping experiment than with the GWAS, which can be explained by the smaller amount of genetic variation represented in the single $F_{1}$ family compared with the overall breeding population, which was derived from thirteen parental individuals. Four QTLs and 15 SNPs were found to have a significant association with more than one trait. This was expected, as the different phenotypes were all deduced from the Peduncle Length and they all then measured the same process underlying growth.

For each trait, the markers found in association were different from a year to another, both in QTL mapping and in GWAS. These differences could be due either to significant loci changing over time, by switching on or off, or to environmental variation, as it was observed in other QTL mapping studies that investigated traits highly affected by the environment (Sun, Niu et al. 2017, Ashton, Ritchie et al. 2019). However, there were some

312 hot spot regions of $0.5 \mathrm{Mb}$ that contained SNPs associated to different traits and different 313 years. Noteworthy is the chromosomic region at the top of LG5, where two hot spots were 314 found, one between 0 and $0.5 \mathrm{Mb}$ (for $\triangle E W$ and $\mathrm{PL}$ in 2018, and H75 and ES in 2019) and one between 1.4 and 1.8 Mb (for $\triangle \mathrm{EW}, \mathrm{H} 25, \mathrm{H} 50$ and PL in 2019). Future studies should 
316 investigate these further. In addition to these hot spots, we also identified SNP regions that

317 were significant in both QTL and GWAS analyses. Specifically, by comparing the relative 318 physical positions of the SNPs, two regions found with QTL mapping appeared to be in 319 close proximity with two significant SNPs identified by GWAS. In particular, the QTLs for $320 \mathrm{H} 25, \mathrm{PL}$, and EW measured in 2017 spanned the 4.45-4.50 Mb region on chromosome 3 321 (corresponding to $23.20-24.90 \mathrm{cM}$ on LG3) and SNP trevally000114_4956408, located at $3224.96 \mathrm{Mb}$ on chromosome 3, was found to be significant for PL in 2019 with GWAS; and the 323 QTLs for $\triangle \mathrm{H} 75$ and $\triangle \mathrm{PL}$ in 2019, encompassing the 25.18-25.21 $\mathrm{Mb}$ region on 324 chromosome 14 (17.02-17.59 on LG14), are close to SNP trevally001025_25939455, 325 located at $25.94 \mathrm{Mb}$ on chromosome 14 and significant for $\Delta \mathrm{H} 50$ and $\triangle \mathrm{PL}$ in 2019 (Figure 326 5, Table 3 and Table S1). Being identified with two different statistical analyses and for 327 multiple traits across two years, these two regions are then of particular interest for the 328 understanding of the genetic determinism of growth in trevally. A BLAST search of the 100 329 kb regions flanking those markers against the NCBI nucleotide database did not return any 330 sequence similarities, indicating that they are located in non-coding or in non-annotated 331 regions. Intergenic regions can still have a functional role in gene expression and 332 regulation (Wyrick and Young 2002). For example, these SNPs could be located in an 333 intron that acts as a regulatory region (promoter, enhancer, silencer or insulator).

334 Compared with the heritability estimates found in Valenza-Troubat et al. (2021), the present analysis still seems underpowered. The range of heritability estimates was moderate to high $(0.67 \pm 0.05$ to $0.76 \pm 0.06)$ for the measured traits $(\mathrm{H} 25, \mathrm{H} 50, \mathrm{H} 75, \mathrm{PL}$ and $\mathrm{EW}$ ) and moderate (ranging from $0.28 \pm 0.07$ to $0.68 \pm 0.07$ ) for the net gain traits $(\Delta \mathrm{H} 25, \Delta \mathrm{H} 50, \Delta \mathrm{H} 75, \Delta \mathrm{PL}$ and $\Delta \mathrm{EW})$, and it remained consistent throughout the experiment. In the present study, PVEs ranged from $22.1 \%$ to $47.36 \%$ for the QTL mapping study and from $4.74 \%$ to $46.81 \%$ for GWAS, indicating that neither techniques were able to capture all of the genetic components of growth traits (Table 4). Additional genetic interactions, other than additive effects, should be considered. While heritability is a key feature of a trait indicating its potential for improvement via selection, polygenic traits are often influenced by non-additive genetic effects such as dominance or epistasis (Glover, Solberg et al. 2017). Understanding the genetic mechanisms that underlie a trait is an important part of explaining phenotypic diversity. This is particularly relevant when looking at traits related to fitness (e.g. growth, shyness, foraging or predator awareness) in 
348 populations that are undergoing domestication but still occasionally interbreed with wild 349 conspecifics (e.g. when new broodstock is caught and added).

\section{$351 \quad$ Future directions}

352 In this study, the combination of QTL mapping and GWAS enabled the identification of 353 genomic regions that control growth in a large captive trevally breeding population. From a 354 farming perspective, parameters such as stocking density (Irwin, O'halloran et al. 1999) or 355 feed availability and quality (Holm, Refstie et al. 1990) can be carefully managed to 356 accelerate fish growth in a land-based aquaculture facility. However, when aiming to 357 develop new species for aquaculture, it is fundamental to understand the genetic 358 architecture of commercially important traits that can potentially be enhanced through 359 selective breeding. The findings of this study provide a useful framework for determining 360 the genetic basis for growth traits in trevally. The identification of multiple QTLs through 361 QTL mapping and genetic markers commonly involved in growth-related traits via GWAS, 362 represents an essential step for the establishment of marker-assisted selection (MAS) 363 breeding programme for trevally. Fine mapping, confirmation and annotation of relevant 364 regions will bring a deeper understanding of the genetic architecture of growth. 


\section{Data Availability Statement}

368

Table S1 contains a list of SNP-trait associations detected with GWAS for height at 25\%, $50 \%$ and $75 \%$ of the peduncle length ( $\mathrm{H} 25, \mathrm{H} 50$ and $\mathrm{H} 75$ respectively), Peduncle Length $(\mathrm{PL})$, Estimated Weight $(\mathrm{EW})$ and net gain traits $(\Delta \mathrm{H} 25, \Delta \mathrm{H} 50, \Delta \mathrm{H} 75, \Delta \mathrm{PL}, \Delta \mathrm{EW})$ in November 2017 (Nov17), October 2018 (Oct18) and November 2019 (Nov19). For each SNP the table show the physical position on the linkage group (LG), the p-value, the minor allele frequency (MAF), the False Discovery Rate (FDR) adjusted p-value and the percentage of variance explained (PVE).

Trevally (araara) are a taonga (treasured) species to Māori, the Indigenous people of Aotearoa New Zealand. All genomic data obtained from taonga species have whakapapa (genealogy that includes people, plants and animals, mountains, rivers and winds) and are therefore taonga in their own right. These data are tapu (sacred) and tikanga (customary practices, protocols, and ethics) determine how people interact with these data. Thus, all the genomic data have been deposited in a managed repository that controls access. Raw and analyzed data are available through the Genomics Aotearoa data repository at https://repo.data.nesi.org.nz/. This was done to recognise Māori as important partners in science and innovation and as inter-generational guardians of significant natural resources and indigenous knowledge.

\section{Acknowledgements}

We would like to acknowledge the PFR staff that assisted with the breeding and husbandry operation for the trevally populations; in particular Warren Fantham who oversees the larvae rearing of finfish and Therese Wells who manages the post-juvenile husbandry. This research was funded through the MBIE Endeavour Programme "Accelerated breeding for enhanced seafood production" (\#C11X1603) to MW. 


\section{References}

394

395

396

397

398

399

400

401

402

403

404

405

406

407

408

409

410

411

412

413

414

415

416

417

418

419

420

421

422

423

424

425

426

427

428

429

430

Andrews, S. (2010). "FastQC: a quality control tool for high throughput sequence data." Aronesty, E. (2013). "Comparison of sequencing utility programs." The Open Bioinformatics Journal 7(1).

Ashton, D. T., E. Hilario, P. Jaksons, P. A. Ritchie and M. Wellenreuther (2019). "Genetic diversity and heritability of economically important traits in the Australasian snapper (Chrysophrys auratus)." Aquaculture 505: 190-198.

Ashton, D. T., P. A. Ritchie and M. Wellenreuther (2017). "15 years of QTL studies in fish: challenges and future directions." Mol Ecol 26: 1465-1476.

Ashton, D. T., P. A. Ritchie and M. Wellenreuther (2019). "High-density linkage map and QTLs for growth in snapper (Chrysophrys auratus)." Genes Genomes Genetics G3 9(4): 1027-1035.

Baranski, M., T. Moen and D. I. Våge (2010). "Mapping of quantitative trait loci for flesh colour and growth traits in Atlantic salmon (Salmo salar)." Genetics Selection Evolution 42(1): 1-14.

Benjamini, Y. and Y. Hochberg (1995). "Controlling the False Discovery Rate: A Practical and Powerful Approach to Multiple Testing." Journal of the Royal Statistical Society. Series B (Methodological) 57(1): 289-300.

Besnier, F., M. F. Solberg, A. C. Harvey, G. R. Carvalho, D. Bekkevold, M. I. Taylor, S. Creer, E. E. Nielsen, Ø. Skaala and F. Ayllon (2020). "Epistatic regulation of growth in Atlantic salmon revealed: a QTL study performed on the domesticated-wild interface." BMC genetics 21(1): 1-17.

Bolger, A. M., M. Lohse and B. Usadel (2014). "Trimmomatic: a flexible trimmer for Illumina sequence data." Bioinformatics 30(15): 2114-2120.

Bray, D. J. (2020). Silver Trevally, Pseudocaranx georgianus (Cuvier 1833). . In Fishes of Australia.

Brett, J. and T. Groves (1979). "Physiological energetics." Fish physiology 8(6): 280-352.

Broad_Institute. (2015). "Picard-tools." from https://broadinstitute.github.io/picard/.

Broman, K. W., H. Wu, Ś. Sen and G. A. Churchill (2003). "R/qtl: QTL mapping in experimental crosses." Bioinformatics 19(7): 889-890.

Camara, M. D. and J. E. Symonds (2014). "Genetic improvement of New Zealand aquaculture species: programmes, progress and prospects." New Zeal J Mar Fresh: 1-26.

Catanach, A., M. Ruigrok, D. Chagné, D. Bowatte, M. Davy, R. Storey, N. Valenza-

Troubat, E. López-Girona, E. Hilario, M. J. Wylie and M. Wellenreuther (2021). "Genomic basis of sex determination in the marine teleost Pseudocaranx georgianus." BMC Genomics.

Catchen, J., P. A. Hohenlohe, S. Bassham, A. Amores and W. A. Cresko (2013). "Stacks: an analysis tool set for population genomics." Mol Ecol 22(11): 3124-3140. 
431 Debes, P. V., N. Piavchenko, A. Ruokolainen, O. Ovaskainen, J. E. Moustakas-Verho, N.

Parre, T. Aykanat, J. Erkinaro and C. R. Primmer (2021). "Polygenic and major-locus contributions to sexual maturation timing in Atlantic salmon." Mol Ecol.

Dmitriew, C. M. (2011). "The evolution of growth trajectories: what limits growth rate?" Biol Rev 86(1): 97-116.

Doerge, R. W. and G. A. Churchill (1996). "Permutation tests for multiple loci affecting a quantitative character." Genet 142(1): 285-294.

Elshire, R. J., J. C. Glaubitz, Q. Sun, J. A. Poland, K. Kawamoto, E. S. Buckler and S. E. Mitchell (2011). "A robust, simple genotyping-by-sequencing (GBS) approach for high diversity species." PLoS ONE 6(5): e19379.

Fraslin, C., E. Quillet, T. Rochat, N. Dechamp, J.-F. Bernardet, B. Collet, D. Lallias and P. Boudinot (2020). "Combining multiple approaches and models to dissect the genetic architecture of resistance to infections in fish." Front Genet 11: 677.

Froese, R., J. T. Thorson and R. Reyes Jr (2014). "A Bayesian approach for estimating length-weight relationships in fishes." Journal of Applied Ichthyology 30(1): 78-85.

Garrison, E. and G. Marth (2012). "Haplotype-based variant detection from short-read sequencing." arXiv:1207.3907 [q-bio].

Gebhardt-Henrich, S. and H. Richner (1998). "Causes of growth variation and its consequences for fitness." Oxford Ornithology Series 8: 324-339.

Glover, K. A., M. F. Solberg, P. McGinnity, K. Hindar, E. Verspoor, M. W. Coulson, M. M. Hansen, H. Araki, Ø. Skaala and T. Svåsand (2017). "Half a century of genetic interaction between farmed and wild Atlantic salmon: status of knowledge and unanswered questions." Fish Fish. 18(5): 890-927.

Griot, R., F. Allal, F. Phocas, S. Brard-Fudulea, R. Morvezen, A. Bestin, P. Haffray, Y. François, T. Morin and C. Poncet (2021). "Genome-wide association studies for resistance to viral nervous necrosis in three populations of European sea bass (Dicentrarchus labrax) using a novel 57k SNP array DlabChip." Aquaculture 530: 735930.

Hayes, B. J., H. A. Lewin and M. E. Goddard (2013). "The future of livestock breeding: genomic selection for efficiency, reduced emissions intensity, and adaptation." Trends Genet 29(4): 206-214.

Holm, J. C., T. Refstie and S. Bø (1990). "The effect of fish density and feeding regimes on individual growth rate and mortality in rainbow trout (Oncorhynchus mykiss)." Aquaculture 89(3-4): 225-232.

Hong, E. P. and J. W. Park (2012). "Sample size and statistical power calculation in genetic association studies." Genomics \& informatics 10(2): 117.

Huisman, J. (2017). "Pedigree reconstruction from SNP data: parentage assignment, sibship clustering and beyond." Mol Ecol Res 17(5): 1009-1024.

Imsland, A. K. and T. M. Jonassen (2003). "Growth and age at first maturity in turbot and halibut reared under different photoperiods." Aquaculture International 11(5): 463-475.

Imsland, A. K. and Ó. D. B. Jónsdóttir (2002). "Is there a genetic basis to growth in Atlantic cod?" Fish Fish. 3(1): 36-52. 
Imsland, A. K., E. Schram, B. Roth, R. Schelvis-Smit and K. Kloet (2007). "Improving growth in juvenile turbot (Scophthalmus maximus Rafinesque) by rearing fish in switched temperature regimes." Aquaculture International 15(5): 403-407.

475

Irwin, S., J. O'halloran and R. FitzGerald (1999). "Stocking density, growth and growth variation in juvenile turbot, Scophthalmus maximus (Rafinesque)." Aquaculture 178(1-2): 77-88.

Jones, G. (1986). "Food availability affects growth in a coral reef fish." Oecologia 70(1): 136-139.

Karås, P. and V. Klingsheim (1997). "Effects of temperature and salinity on embryonic development of turbot (Scophthalmus maximus L.) from the North Sea, and comparisons with Baltic populations." Helgoländer Meeresuntersuchungen 51 (2): 241.

Liu, F., F. Sun, J. H. Xia, J. Li, G. H. Fu, G. Lin, R. J. Tu, Z. Y. Wan, D. Quek and G. H. Yue (2014). "A genome scan revealed significant associations of growth traits with a major QTL and GHR2 in tilapia." Scientific reports 4(1): 1-9.

Liu, X., M. Huang, B. Fan, E. S. Buckler and Z. Zhang (2016). "Iterative usage of fixed and random effect models for powerful and efficient genome-wide association studies." PLos Genet 12(2): e1005767.

Liu, Y., H. Wang, H. Wen, Y. Shi, M. Zhang, X. Qi, K. Zhang, Q. Gong, J. Li and F. He (2020). "First high-density linkage map and QTL fine mapping for growth-related traits of spotted sea bass (Lateolabrax maculatus)." Marine Biotechnology 22(4): 526-538.

Mackay, T. F. (2001). "The genetic architecture of quantitative traits." Annu Rev Genet 35: 303-339.

Meuwissen, T. and M. Goddard (2010). "Accurate prediction of genetic values for complex traits by whole-genome resequencing." Genet 185(2): 623-631.

Ministry for Primary Industries (2014). Trevally (TRE). Fisheries Assessment Plenary. Wellington, New Zealand, Ministry for Primary Industries.

Newell, M., D. Cook, N. Tinker and J.-L. Jannink (2011). "Population structure and linkage disequilibrium in oat (Avena sativa L.): implications for genome-wide association studies." Theoretical and Applied Genetics 122(3): 623-632.

Nguyen, N. H., P. Rastas, H. Premachandra and W. Knibb (2018). "First high-density linkage map and single nucleotide polymorphisms significantly associated with traits of economic importance in Yellowtail Kingfish Seriola lalandi." Front Genet 9: 127.

Palaiokostas, C., M. Kocour, M. Prchal and R. D. Houston (2018). "Accuracy of genomic evaluations of juvenile growth rate in common carp (Cyprinus carpio) using genotyping by sequencing." Front Genet 9: 82.

Pedersen, T. and M. Jobling (1989). "Growth rates of large, sexually mature cod Gadus morhua, in relation to condition and temperature during an annual cycle." Aquaculture 81(2): 161-168.

R Development Core Team. (2016). "R: A Language and Environment for Statistical Computing." Retrieved 12-Dec-2016, 2016, from http://www.R-project.org/.

Rastas, P., L. Paulin, I. Hanski, R. Lehtonen and P. Auvinen (2013). "Lep-MAP: fast and accurate linkage map construction for large SNP datasets." Bioinformatics 29. 
514 Santure, A. W. and D. Garant (2018). "Wild GWAS—association mapping in natural 515 populations." Mol Ecol Res 18(4): 729-738.

516 Sinnott-Armstrong, N., Y. Tanigawa, D. Amar, N. Mars, C. Benner, M. Aguirre, G. R. Venkataraman, M. Wainberg, H. M. Ollila and T. Kiiskinen (2021). "Genetics of 35 blood and urine biomarkers in the UK Biobank." Nat Genet 53(2): 185-194.

Smith-Vaniz, W. F. and H. L. Jelks (2006). "Australian trevallies of the genus Pseudocaranx (Teleostei: Carangidae), with description of a new species from Western Australia." Memoirs of Museum Victoria 63(1): 97-106.

Sun, C., Y. Niu, X. Ye, J. Dong, W. Hu, Q. Zeng, Z. Chen, Y. Tian, J. Zhang and M. Lu (2017). "Construction of a high-density linkage map and mapping of sex determination and growth-related loci in the mandarin fish (Siniperca chuatsi)." BMC genomics 18(1): 1-10.

Symonds, J. E., S. M. Clarke, N. King, S. P. Walker, B. Blanchard, D. Sutherland, R. Roberts, M. A. Preece, M. Tate and P. Buxton (2019). "Developing Successful Breeding Programs for New Zealand Aquaculture: A Perspective on Progress and Future Genomic Opportunities." Front Genet 10: 27.

Tsai, H.-Y., A. Hamilton, A. E. Tinch, D. R. Guy, K. Gharbi, M. J. Stear, O. Matika, S. C. Bishop and R. D. Houston (2015). "Genome wide association and genomic prediction for growth traits in juvenile farmed Atlantic salmon using a high density SNP array." BMC Genomics 16: 969-969.

Valenza-Troubat, N., S. Montanari, P. Morrison-Whittle, P. A. Ritchie and M. Wellenreuther (2021). "Evaluating new species for aquaculture: A genomic dissection of growth in the New Zealand silver trevally (Pseudocaranx georgianus)." Evol Appl.

Voorrips, R. (2002). "MapChart: software for the graphical presentation of linkage maps and QTLs." Journal of heredity 93(1): 77-78.

Wang, J. and Z. Zhang (2021). "GAPIT Version 3: boosting power and accuracy for genomic association and prediction." Genomics, Proteomics \& Bioinformatics.

Weatherley, A. H. (1972). "Growth and ecology of fish populations."

Wellenreuther, M. and B. Hansson (2016). "Detecting polygenic evolution: problems, pitfalls, and promises." Trends Genet 32(3): 155-164.

Wieters, B., K. A. Steige, F. He, E. M. Koch, S. E. Ramos-Onsins, H. Gu, Y.-L. Guo, S. Sunyaev and J. de Meaux (2021). "Polygenic adaptation of rosette growth in Arabidopsis thaliana." PLos Genet 17(1): e1008748.

Wyrick, J. J. and R. A. Young (2002). "Deciphering gene expression regulatory networks." Current opinion in genetics \& development 12(2): 130-136. (2020). "Identification of candidate growth-related SNPs and genes using GWAS in brownmarbled grouper (Epinephelus fuscoguttatus)." Marine Biotechnology 22(2): 153-166. 


\section{Tables}

553 Table 1: Summary of the phenotypes height at $25 \%, 50 \%$ and $75 \%$ of the body ( $\mathrm{H} 25, \mathrm{H} 50$ 554 and $\mathrm{H} 75$ respectively), Peduncle Length (PL), estimated weight (EW) and net gains traits 555 associated $(\Delta \mathrm{H} 25, \Delta \mathrm{H} 50, \Delta \mathrm{H} 74, \Delta \mathrm{PL}$ and $\Delta \mathrm{EW}$ respectively) across the whole $\mathrm{F} 1$ 556 population and for the largest family. Included are the number offspring phenotyped $(n)$, 557 mean, and standard deviation (SD).

\begin{tabular}{|c|c|c|c|c|c|c|}
\hline & \multicolumn{2}{|c|}{ Nov 2017} & \multicolumn{2}{|c|}{ Oct 2018} & \multicolumn{2}{|c|}{ Nov 2019} \\
\hline \multirow[t]{2}{*}{ All } & \multicolumn{2}{|c|}{$n=1,094$} & \multicolumn{2}{|c|}{$n=719$} & \multicolumn{2}{|c|}{$n=694$} \\
\hline & Mean & SD & Mean & SD & Mean & SD \\
\hline H25 & 49.71 & 9.02 & 66.94 & 13.51 & 90.10 & 15.70 \\
\hline $\mathrm{H} 50$ & 59.45 & 11.02 & 79.99 & 16.39 & 105.53 & 18.65 \\
\hline $\mathrm{H} 75$ & 48.58 & 9.91 & 61.26 & 12.69 & 85.63 & 15.80 \\
\hline $\mathrm{PL}$ & 156.79 & 23.92 & 200.64 & 35.36 & 264.09 & 40.44 \\
\hline EW & 89.90 & 41.85 & 191.93 & 99.89 & 426.34 & 177.93 \\
\hline$\Delta \mathrm{H} 25$ & & & 15.85 & 7.80 & 39.08 & 11.21 \\
\hline$\Delta \mathrm{H} 50$ & & & 18.75 & 8.42 & 44.34 & 12.36 \\
\hline$\Delta \mathrm{H} 75$ & & & 11.08 & 6.77 & 35.54 & 10.19 \\
\hline$\triangle \mathrm{PL}$ & & & 40.03 & 18.00 & 103.59 & 27.31 \\
\hline$\Delta \mathrm{EW}$ & & & 95.83 & 64.45 & 330.78 & 147.12 \\
\hline \multirow[t]{2}{*}{ Family } & \multicolumn{2}{|c|}{$n=87$} & \multicolumn{2}{|c|}{$n=68$} & \multicolumn{2}{|c|}{$n=67$} \\
\hline & Mean & SD & Mean & SD & Mean & SD \\
\hline $\mathrm{H} 25$ & 52.21 & 7.95 & 73.71 & 11.32 & 96.52 & 12.64 \\
\hline $\mathrm{H} 50$ & 63.10 & 9.29 & 86.87 & 13.41 & 111.90 & 14.77 \\
\hline $\mathrm{H} 75$ & 52.85 & 8.99 & 66.72 & 9.75 & 92.36 & 12.39 \\
\hline $\mathrm{PL}$ & 167.59 & 21.32 & 218.19 & 30.04 & 280.78 & 33.07 \\
\hline$\overline{E W}$ & 107.43 & 37.85 & 238.01 & 89.61 & 498.52 & 159.82 \\
\hline$\Delta \mathrm{H} 25$ & & & 20.43 & 6.53 & 42.78 & 9.21 \\
\hline$\Delta \mathrm{H} 50$ & & & 22.46 & 6.92 & 46.84 & 9.89 \\
\hline$\Delta \mathrm{H} 75$ & & & 12.88 & 5.54 & 37.79 & 8.33 \\
\hline$\Delta \mathrm{PL}$ & & & 47.91 & 15.91 & 109.31 & 23.15 \\
\hline$\Delta \mathrm{EW}$ & & & 125.99 & 60.54 & 384.63 & 135.00 \\
\hline
\end{tabular}


560 Table 2: Marker statistics of the linkage map constructed from the largest trevally family.

\begin{tabular}{|c|c|c|c|}
\hline LG & $\begin{array}{l}\text { Number of } \\
\text { markers }^{\mathrm{a}}\end{array}$ & Length (cM) & $\begin{array}{c}\text { Average } \\
\text { distance } \\
\text { between } \\
\text { markers (cM) }\end{array}$ \\
\hline 1 & 85 & 61.27 & 0.72 \\
\hline 2 & 80 & 58.41 & 0.73 \\
\hline 3 & 81 & 57.26 & 0.71 \\
\hline 4 & 68 & 49.34 & 0.73 \\
\hline 5 & 81 & 56.69 & 0.70 \\
\hline 6 & 65 & 51.72 & 0.80 \\
\hline 7 & 87 & 60.09 & 0.69 \\
\hline 8 & 70 & 48.14 & 0.69 \\
\hline 9 & 78 & 54.43 & 0.70 \\
\hline 10 & 84 & 57.22 & 0.68 \\
\hline 11 & 82 & 61.88 & 0.75 \\
\hline 12 & 71 & 49.30 & 0.69 \\
\hline 13 & 79 & 59.00 & 0.75 \\
\hline 14 & 64 & 53.51 & 0.84 \\
\hline 15 & 67 & 52.84 & 0.79 \\
\hline 16 & 67 & 56.27 & 0.84 \\
\hline 17 & 108 & 82.89 & 0.77 \\
\hline 18 & 82 & 54.95 & 0.67 \\
\hline 19 & 80 & 53.82 & 0.67 \\
\hline 20 & 71 & 55.04 & 0.78 \\
\hline 21 & 65 & 52.83 & 0.81 \\
\hline 22 & 73 & 49.29 & 0.68 \\
\hline 23 & 63 & 45.39 & 0.72 \\
\hline 24 & 79 & 53.88 & 0.68 \\
\hline Total & 1,830 & 1.335 .46 & 0.73 \\
\hline
\end{tabular}


563 Table 3: List of significant Quantitative Trait Loci (QTL) detected for height at 25\% and $56475 \%$ of the peduncle length (H25 and H75 respectively), Peduncle Length (PL), Estimated 565 Weight $(E W)$ and net gain for $\mathrm{H} 75(\Delta \mathrm{H} 75)$ and $\mathrm{PL}(\Delta \mathrm{PL})$ in November 2017 (Nov17) and 566 November 2019 (Nov19), using a high-density linkage map. For each QTL the position on 567 the linkage group (LG), the significance threshold, the LOD at the peak, the SNP name 568 and the percentage of variance explained (PVE) are shown.

\begin{tabular}{|c|c|c|c|c|c|c|c|}
\hline Time & Trait & LG & $\begin{array}{c}\text { Peak } \\
\text { position } \\
(\mathbf{c M})\end{array}$ & SNP at peak & $\begin{array}{c}\text { LOD } \\
\text { threshold }\end{array}$ & $\begin{array}{c}\text { LOD } \\
\text { at } \\
\text { peak }\end{array}$ & $\begin{array}{c}\text { PVE } \\
\text { (\%) }\end{array}$ \\
\hline Nov17 & $\mathrm{H} 25$ & 3 & 23.2 & trevally000114_4454829 & 4.71 & 4.73 & 22.1 \\
\hline Nov17 & $\mathrm{PL}$ & 3 & 24.9 & trevally000114_4498123 & 4.71 & 4.83 & 22.6 \\
\hline Nov17 & $\mathrm{EW}$ & 3 & 24.9 & trevally000114_4498123 & 4.60 & 5.39 & 24.8 \\
\hline Nov17 & $\mathrm{H} 75$ & 3 & 52.1 & trevally000114_23355470 & 4.64 & 5.50 & 25.3 \\
\hline Nov17 & $\mathrm{PL}$ & 18 & 0.0 & trevally001200_2242455 & 4.71 & 4.88 & 22.8 \\
\hline Nov17 & $\mathrm{EW}$ & 18 & 0.0 & trevally001200_2242455 & 4.60 & 4.82 & 22.5 \\
\hline Nov19 & $\Delta \mathrm{PL}$ & 14 & 17.0 & trevally001025_25205374 & 4.81 & 5.41 & 31.0 \\
\hline Nov19 & $\mathrm{AH75}$ & 14 & 17.6 & trevally001025_25180484 & 4.69 & 7.36 & 39.7 \\
\hline
\end{tabular}


571 Table 4: Comparison of heritability estimates found in Valenza-Troubat et al. (2021) and

572 Percentage of Variance Explained (PVE) by Quantitative Trait Loci (QTL) found in interval 573 mapping and markers from the Genome Wide Association Study (GWAS). Data are shown 574 for phenotypes height at 25\%,50\% and $75 \%$ of the body ( $\mathrm{H} 25, \mathrm{H} 50$ and $\mathrm{H} 75$ respectively), 575 Peduncle Length $(\mathrm{PL})$, estimated weight $(\mathrm{EW})$ and net gains traits associated $(\Delta \mathrm{H} 25$, $576 \Delta \mathrm{H} 50, \Delta \mathrm{H} 74, \Delta \mathrm{PL}$ and $\Delta \mathrm{EW}$ respectively) in November 2017 (Nov17), October 2018 577 (Oct18) and November 2019 (Nov19).

\begin{tabular}{|c|c|c|c|c|}
\hline Time & Trait & Heritability & PVE QTL (\%) & PVE GWAS (\%) \\
\hline Nov17 & $\mathrm{H} 25$ & $0.67 \pm 0.05$ & 22.1 & 18.4 \\
\hline Nov17 & $\mathrm{H} 50$ & $0.75 \pm 0.05$ & -- & 24.2 \\
\hline Nov17 & $\mathrm{H} 75$ & $0.73 \pm 0.05$ & 25.3 & 38.5 \\
\hline Nov17 & $\mathrm{PL}$ & $0.74 \pm 0.05$ & 45.3 & 28.8 \\
\hline Nov17 & EW & $0.75 \pm 0.05$ & 47.4 & 42.3 \\
\hline Oct18 & $\mathrm{H} 25$ & $0.74 \pm 0.05$ & -- & 38.6 \\
\hline Oct18 & $\mathrm{H} 50$ & $0.75 \pm 0.05$ & -- & 24.2 \\
\hline Oct18 & $\mathrm{H} 75$ & $0.68 \pm 0.05$ & -- & 4.7 \\
\hline Oct18 & $\mathrm{PL}$ & $0.70 \pm 0.05$ & -- & 40.6 \\
\hline Oct18 & EW & $0.70 \pm 0.05$ & -- & 5.3 \\
\hline Oct18 & $\Delta \mathrm{H} 25$ & $0.46 \pm 0.05$ & -- & 10.9 \\
\hline Oct18 & $\Delta \mathrm{H} 50$ & $0.52 \pm 0.05$ & -- & 43.5 \\
\hline Oct18 & $\Delta \mathrm{H} 75$ & $0.28 \pm 0.05$ & -- & -- \\
\hline Oct18 & $\Delta \mathrm{PL}$ & $0.47 \pm 0.05$ & -- & 46.8 \\
\hline Oct18 & $\Delta \mathrm{EW}$ & $0.63 \pm 0.05$ & -- & 18.0 \\
\hline Nov19 & $\mathrm{H} 25$ & $0.73 \pm 0.05$ & -- & 20.3 \\
\hline Nov19 & $\mathrm{H} 50$ & $0.72 \pm 0.05$ & -- & 41.6 \\
\hline Nov19 & $\mathrm{H} 75$ & $0.68 \pm 0.05$ & -- & 31.2 \\
\hline Nov19 & $\mathrm{PL}$ & $0.69 \pm 0.05$ & -- & 26.4 \\
\hline Nov19 & EW & $0.72 \pm 0.05$ & -- & 21.4 \\
\hline Nov19 & $\Delta \mathrm{H} 25$ & $0.56 \pm 0.05$ & -- & 16.1 \\
\hline Nov19 & $\Delta \mathrm{H} 50$ & $0.54 \pm 0.05$ & -- & 15.2 \\
\hline Nov19 & $\Delta \mathrm{H} 75$ & $0.43 \pm 0.05$ & 39.7 & -- \\
\hline Nov19 & $\Delta \mathrm{PL}$ & $0.51 \pm 0.05$ & 31.0 & 21.7 \\
\hline Nov19 & $\Delta \mathrm{EW}$ & $0.68 \pm 0.05$ & -- & 11.9 \\
\hline
\end{tabular}




\section{Figures}

581

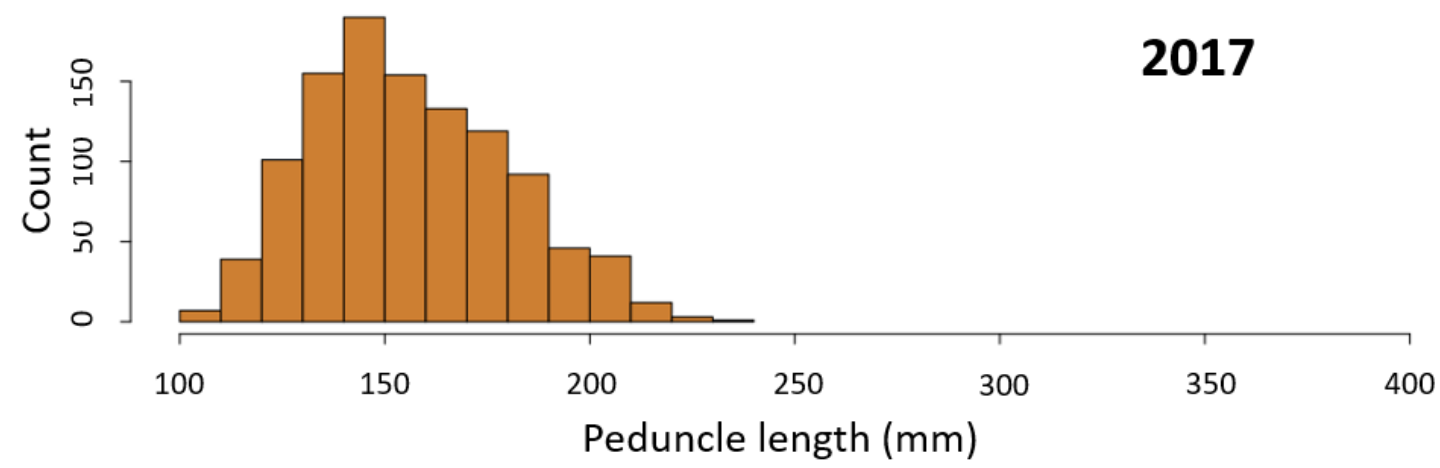

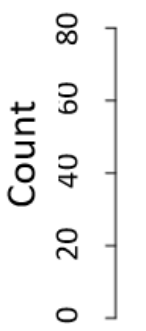

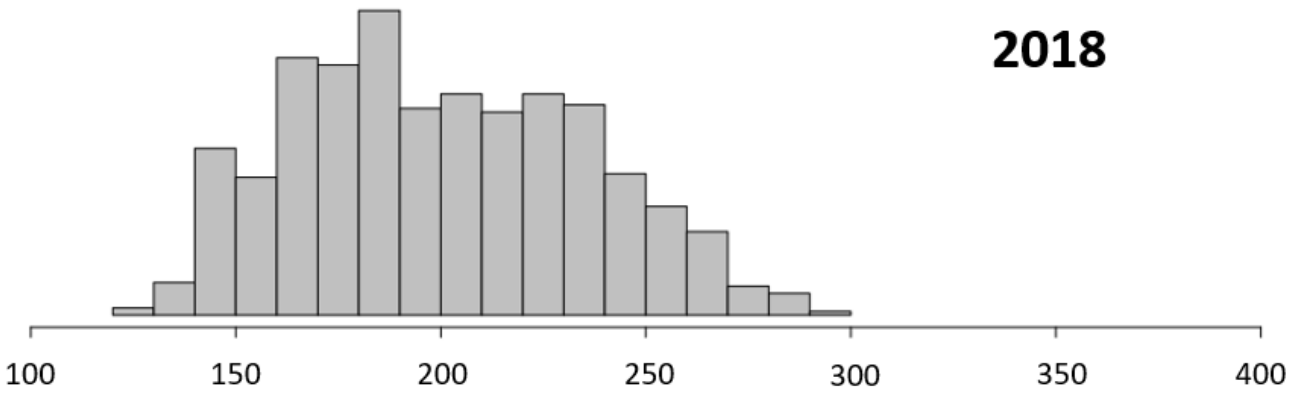

Peduncle length $(\mathrm{mm})$

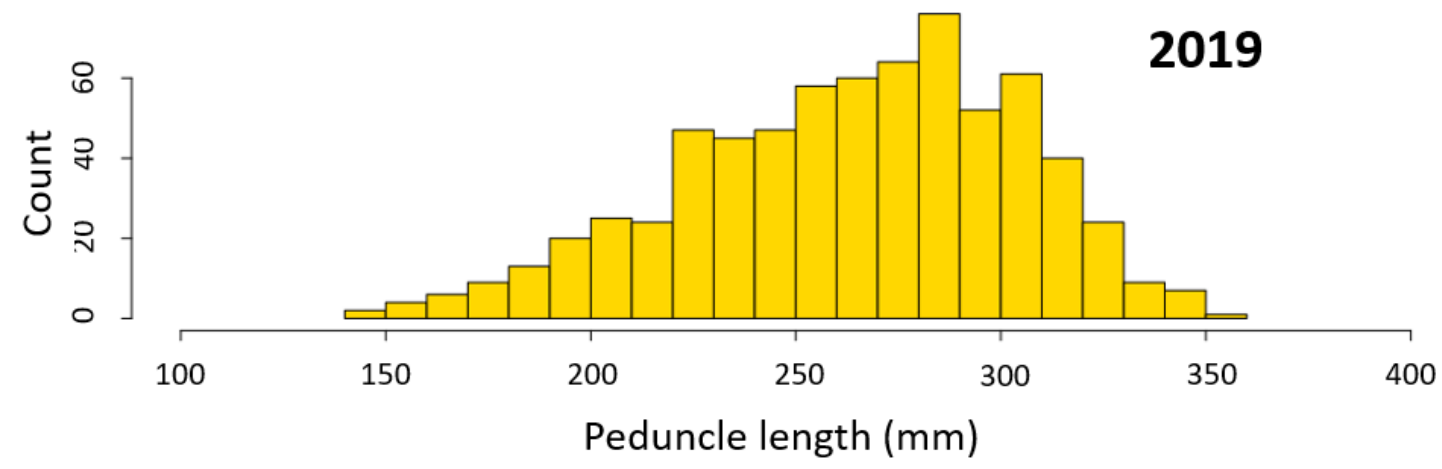

583 Figure 1: Distribution of the peduncle length measurements in November $2017(n=1,094)$, 584 October $2018(n=719)$ and November $2019(n=694)$. 
Linkage group

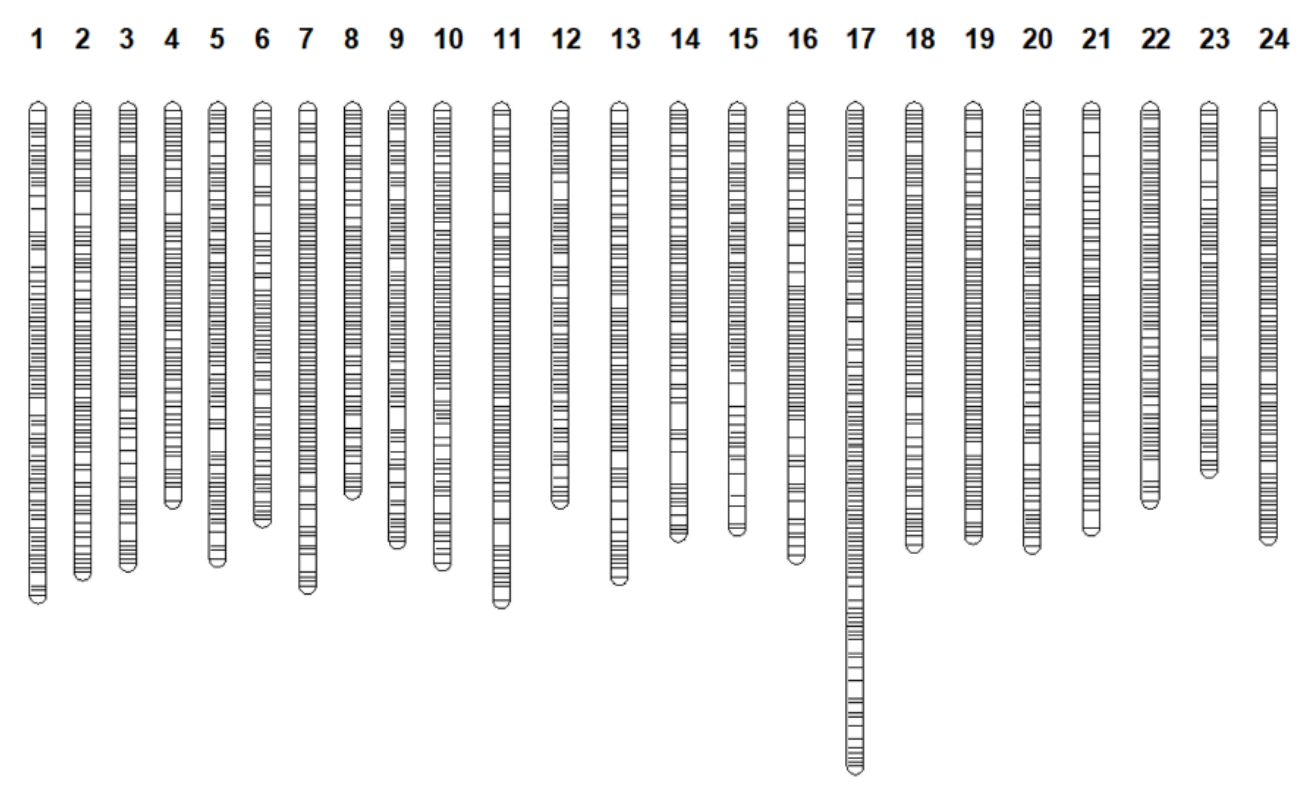

587 Figure 2: Visualisation of the sex-averaged map built for the largest segregating family $(\mathrm{n}=$ 588 87). The 24 linkage groups represent the expected 24 Pseudocaranx georgianus 589 chromosomes 


\section{LG 3}

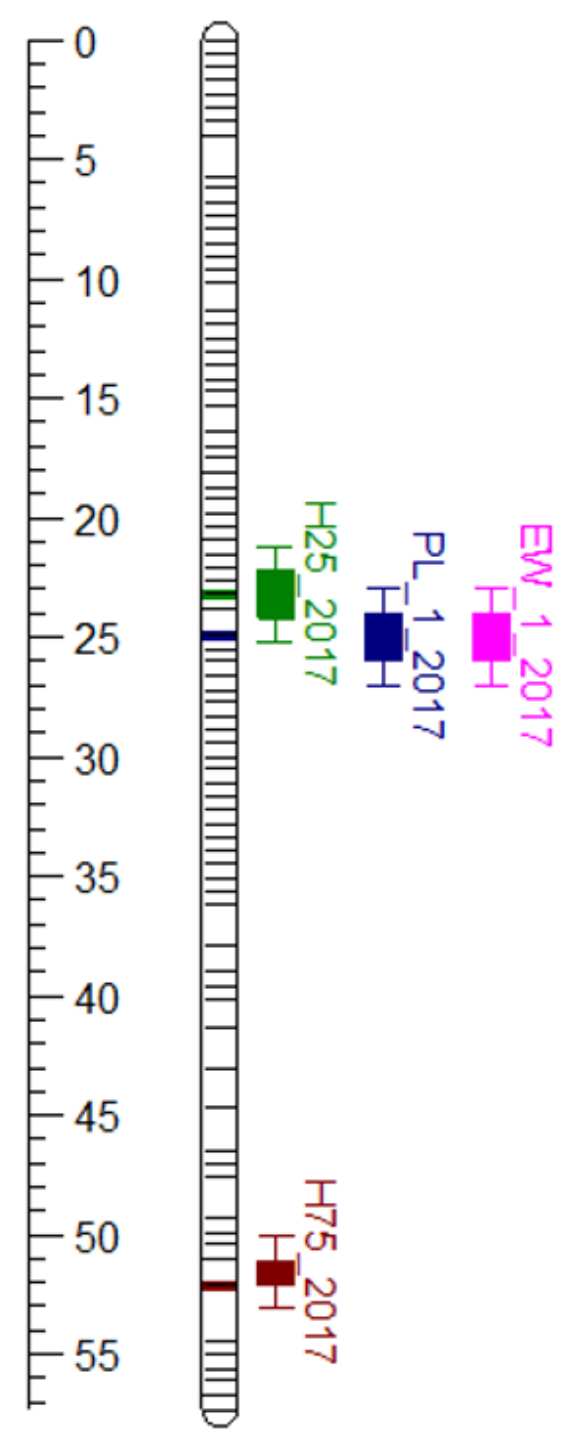

LG 14

\section{LG 18}
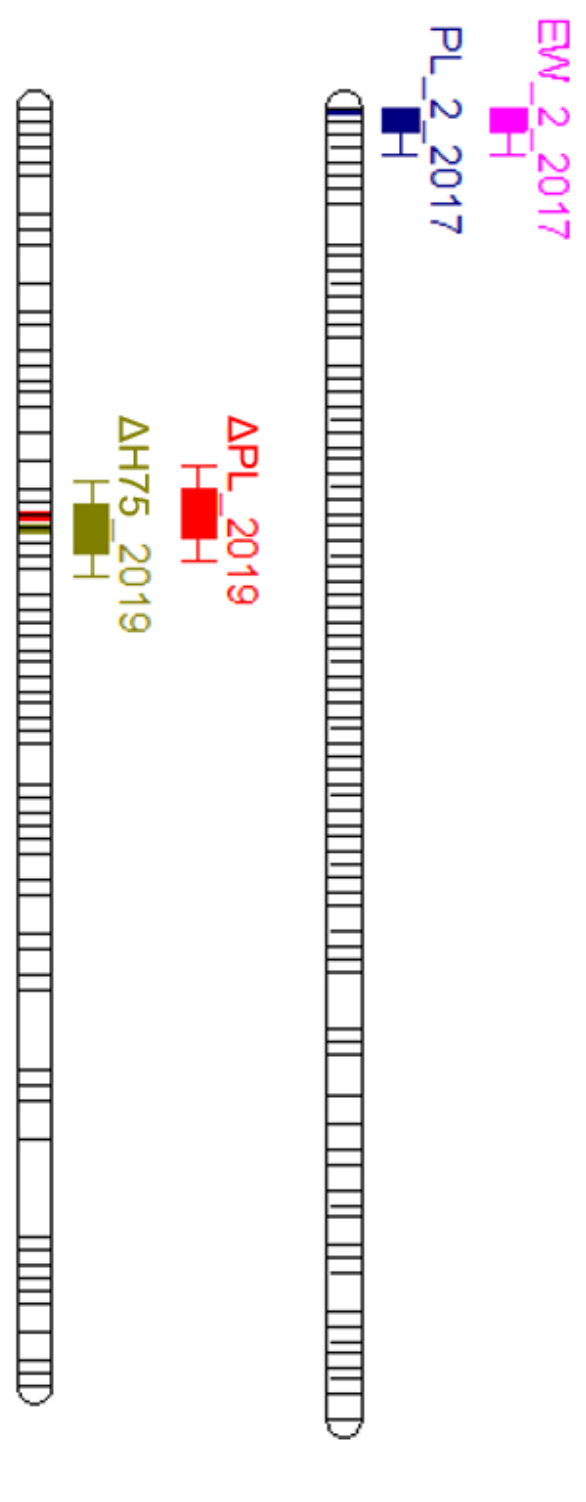

592

Figure 3: Eight significant Quantitative Trait Loci (QTL) associated with growth traits were found in trevally, across three linkage groups (LG3, LG14 and LG18). In November 2017, two QTLs were found associated with peduncle length (PL_1_2017 and PL_2_2017, on LG3 and LG18 respectively), which were also associated with estimated weight (EW_1_2017 and EW_2_2017). In the same year, two more QTLs were found associated with height at 25\% (H75_2017) and 75\% (H75_2017) of the peduncle length, both on LG3. Finally, two QTLs were found in November 2019, one for net gain in peduncle length $\left(\triangle P L \_2019\right)$ and one for net gain in height at $75 \%$ of the peduncle length $\left(\Delta \mathrm{H} 75 \_2019\right)$, both on LG14. 
A

\begin{tabular}{|c|c|c|}
\hline Number of PCs/Covariates & BIC & log Likelihood Function Value \\
\hline 0 & -3021.04 & -3011.33 \\
\hline 1 & -3024.27 & -3011.33 \\
\hline 2 & -3026.99 & -3010.81 \\
\hline 3 & -3030.18 & -3010.76 \\
\hline 4 & -3032.62 & -3009.96 \\
\hline 5 & -3034.96 & -3009.07 \\
\hline 6 & -3038.21 & -3009.07 \\
\hline 7 & -3041.30 & -3008.93 \\
\hline 8 & -3044.39 & -3008.78 \\
\hline 9 & -3047.61 & -3008.77 \\
\hline 10 & -3050.88 & -3008.80 \\
\hline
\end{tabular}

B

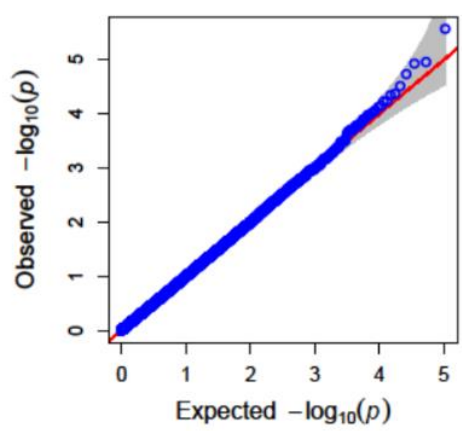

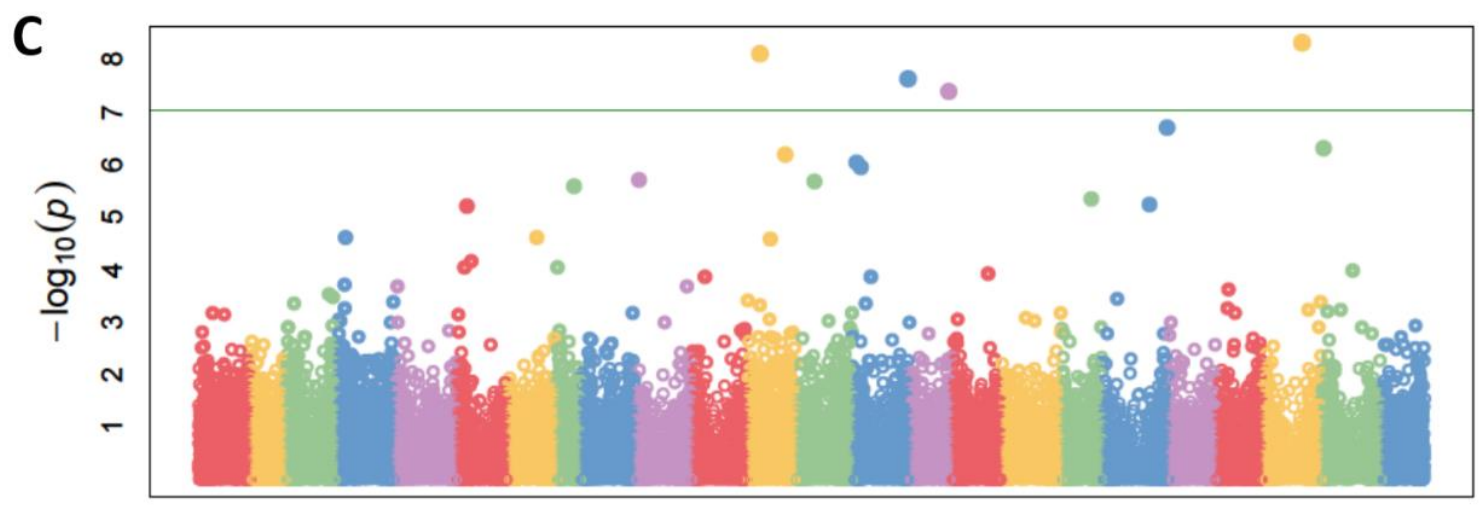

$\begin{array}{llllllllllllllllllllllll}1 & 2 & 3 & 4 & 5 & 6 & 7 & 8 & 9 & 10 & 11 & 12 & 13 & 14 & 15 & 16 & 17 & 18 & 19 & 20 & 21 & 22 & 23 & 24\end{array}$

604 Figure 4: GWAS results for the net gain in peduncle length $(\triangle P L)$ in November 2019. $(A)$ 605 Summary of Bayesian information criterion (BIC) for the optimal number of Principal 606 Components (PCs) to use in the model. (B) Quantile-Quantile (QQ)-plot of p-values. On 607 the $Y$-axis is the observed negative base 10 logarithm of the $p$-values, and on the $X$-axis 608 the expected observed negative base 10 logarithm of the $p$-values under the assumption 609 that the p-values follow a uniform [0 to 1] distribution. The grey area shows the $95 \%$ 610 confidence interval for the QQ-plot under the null hypothesis of no association between the 611 SNP and the trait. (C) Manhattan plot of the results of the GWAS. On the X-axis is the 612 physical position of the SNPs on the genome divided by chromosomes, and on the $\mathrm{Y}$-axis 613 is the negative log base 10 of the p-values. The horizontal green line represents the 614 significance threshold. 


\section{LG14}
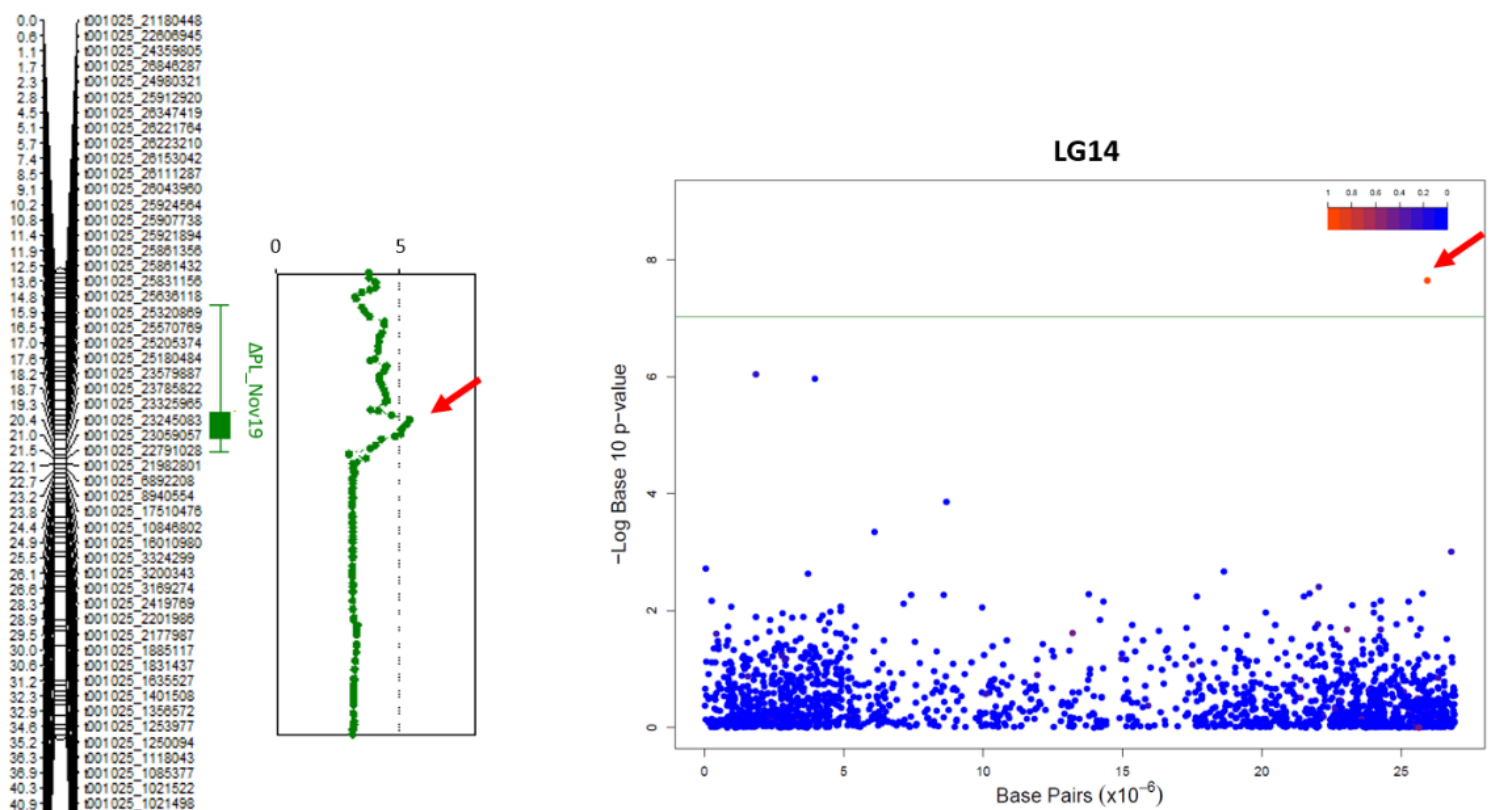

615

616 Figure 5: Comparison of Quantitative Trait Loci (left) and SNP associated (right) with the 617 net gain in peduncle length $(\Delta \mathrm{PL})$ in November 2019. 